\title{
Marketing research centers: community, productivity, and relevance
}

\author{
Robert W. Palmatier ${ }^{1}$
}

Published online: 3 May 2017

(C) Academy of Marketing Science 2017

Business schools, especially in their marketing departments, increasingly feature diverse forms of research centers. That is, marketing departments have long organized centers focused on personal selling or retailing, with the primary goal of placing undergraduate students into sales or retail positions (i.e., some of the most popular job categories for undergraduate marketing students). But more recent iterations of these centers have evolved, creating notable platforms for generating high quality research (e.g., Sales Excellence Institute at the University of Houston) ${ }^{1}$ and establishing communities of researchers (in this issue, see Ahearne 2017).

Other business schools and marketing departments build centers and link them to their executive education programs, in an effort to build relationships with alumni and business leaders and thereby promote the executive education programs. These centers may generate research from these efforts, often as a secondary purpose, typically targeting more managerially focused publication outlets (e.g., HBR, Sloan). This targeting is understandable; such outlets offer wider business readership than the more narrowly focused, less accessible academic outlets. Papers produced by these centers, though sometimes highly cited, often promote consultinglike processes or offer vast integrative frameworks.

Still other centers focus on a specific research domain, as exemplified by the Center for Services Leadership (CSL) ${ }^{2}$ at Arizona State University and the Institute for the Study of

\footnotetext{
$\overline{{ }^{1} \text { http://www.bauer.uh.edu/sei/index.php. }}$

2 https://wpcarey.asu.edu/research/services-leadership.

Robert W. Palmatier

palmatrw@uw.edu

1 Foster School of Business, University of Washington, Box: 353226 , Seattle, WA 98195-3226, USA
}

Business Markets (ISBM) ${ }^{3}$ at Pennsylvania State University (in this issue, see Lilien 2017). In these cases, the research centers maintain links with a strong advisory board, help direct a domain-focused research agenda (services, B2B), provide some limited funding, and, perhaps most importantly, establish a strong community and networking forum for like-minded researchers (e.g., ISBM conferences). Building a strong, domain-specific community is especially critical for emerging research domains and "lone wolf" researchers who may be the only representatives of a particular domain at their home university. The community aspect of these domainspecific centers thus is an important element of the success of many junior scholars, as well as the development of new domains.

The Center for Excellence in Brand and Customer Management $(\mathrm{CEBCM})^{4}$ at Georgia State University has raised the bar even further for centers in marketing. It is described in detail by Kumar (2017) in this issue. For this commentary though, I focus on two benefits, beyond building the domain-specific community, that can be created by centers that adopt the CEBCM model, with the potential to exert transformative changes for marketing research at business schools: enhancements to productivity and enhancements to relevance.

Productivity enhancements at research centers typically result from five key factors: (1) strong leadership by an individually successful scholar (or small core team of scholars), (2) a dedicated focus on producing programmatically impactful research, (3) strong linkages to practicing managers through an executive advisory board or network that grants access to leading-edge challenges and hard-to-access data opportunities (e.g., longitudinal data, customer-level objective performance

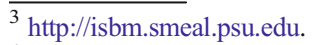

${ }^{4} \mathrm{http}: / /$ cebcm.robinson.gsu.edu.
} 
outcomes, field experiments), (4) diverse teams of students, postdoctoral researchers, and professors who provide continuous, multilevel learning and synergistic combinations of research skills, and (5) a relational community of like-minded scholars offering inspiration and purpose to participants. Accordingly, many of the most productive scholars are associated with a research center; for consumer behavior researchers, a well-established lab and research team $(\mathrm{PhD} \mathrm{stu-}$ dents, postdoctoral researchers) are critical factors. The research models for these centers are growing increasingly similar to those established in other, non-business research areas (e.g., physical sciences, engineering, psychology).

The increased relevance to key stakeholders (i.e., companies, alumni, and students) of programmatic research from managerially focused centers exists because groups of business executives meet regularly with members of the center, help direct the research agenda, and provide access to pertinent data to study real-world, current business problems effectively. This data access allows researchers to focus on problems that are important to managers, rather than restricting their research agenda to available secondary data or accessible experimental samples. Many research trends (e.g., endogeneity concerns, focus on marketing dynamics, desire for field experiments) are further increasing researchers' need to access robust data for publication success, but firms' simultaneous concerns about privacy and general resource constraints are making data collection more difficult. These parallel trends thus are increasing the potential impact of research centers, with huge payoffs for business school stakeholders and researchers. The impact of enhanced research productivity in academic and managerially focused journals for individual scholars and business school rankings is straightforward; the benefits to alumni and donor relations due to the production of managerially relevant research is often overlooked, as are the spillover benefits for students' learning and job placement.

Acknowledgment of the operational and research impact of the CEBCM, ISBM, and CSL research centers was instrumental to the design and launch of the Center for Sales and Marketing Strategy at the University of Washington. ${ }^{5}$ This center uses a different business model, with significantly less infrastructure (no paid staff), such that the virtual, multisided platform connects 20 executive advisory board members, thousands of sales and marketing professionals, and 30 affiliated, managerially focused researchers at universities around the world to enhance research impact, productivity, and relevance, as well as develop a community of managerial researchers.

Among the many models for research centers and labs, developing or being associated with a research center or laboratory can be critical for both researchers and business schools that seek to enhance their research productivity and impact in the future. Visiting these centers in person and realizing the impacts on research productivity and relevance, as well as on students' learning and the development of strong communities, has made believers out of many academics.

\section{References}

Ahearne, M. (2017). Research centers, business schools, and the world of sales. Journal of the Academy of Marketing Science, 45(4). doi: 10.1007/s11747-017-0536-7

Kumar, V. (2017) The role of university research centers in promoting research. Journal of the Academy of Marketing Science, 45(4). doi: 10.1007/s11747-016-0496-3

Lilien, G. L. (2017). Perspectives on university research centers: Lessons from the ISBM. Journal of the Academy of Marketing Science, 45(4). doi:10.1007/s11747-017-0537-6

\footnotetext{
${ }^{5} \mathrm{http}: / / \mathrm{www} \cdot$ salesmarketingcenter.com/.
} 